\title{
Amino Acids Attenuate Insulin Action on Gluconeogenesis and Promote Fatty Acid Biosynthesis via mTORC1 Signaling Pathway in trout Hepatocytes
}

\author{
Weiwei Dai Stéphane Panserat Elisabeth Plagnes-Juan Iban Seiliez \\ Sandrine Skiba-Cassy
}

INRA, UR 1067 Nutrition, Métabolisme, Aquaculture, Pole d'hydrobiologie, CD 918, Saint-Pée-surNivelle, France

\section{Key Words}

Amino acids $\bullet$ mTORC1 $\bullet$ Insulin action • Fatty acid biosynthesis • Gluconeogenesis $•$ Rainbow trout

\begin{abstract}
Background/Aims: Carnivores exhibit poor utilization of dietary carbohydrates and glucose intolerant phenotypes, yet it remains unclear what are the causal factors and underlying mechanisms. We aimed to evaluate excessive amino acids (AAs)-induced effects on insulin signaling, fatty acid biosynthesis and glucose metabolism in rainbow trout and determine the potential involvement of mTORC1 and p38 MAPK pathway. Methods: We stimulated trout primary hepatocytes with different AA levels and employed acute administration of rapamycin to inhibit mTORC1 activation. Results: Increased AA levels enhanced the phosphorylation of ribosomal protein S6 kinase (S6K1), S6, and insulin receptor substrate 1 (IRS-1) on Ser ${ }^{302}$ but suppressed Akt and p38 phosphorylation; up-regulated the expression of genes related to gluconeogenesis and fatty acid biosynthesis. mTORC1 inhibition not only inhibited the phosphorylation of mTORC1 downstream targets, but also blunted IRS-1 Ser ${ }^{302}$ phosphorylation and restored excessive AAs-suppressed Akt phosphorylation. Rapamycin also inhibited fatty acid biosynthetic and gluconeogenic gene expression. Conclusion: High levels of AAs upregulate hepatic fatty acid biosynthetic gene expression through an mTORC1-dependent manner, while attenuate insulin-mediated repression of gluconeogenesis through elevating IRS- 1 Ser $^{302}$ phosphorylation, which in turn impairs Akt activation and thereby weakening insulin action. We propose that p38 MAPK probably also involves in these AAs-induced metabolic changes.
\end{abstract}




\section{Introduction}

The liver is a key organ in the systemic response to insulin, controlling both glucose and lipid metabolism [1]. In hepatocytes, binding of insulin to their receptors leads to recruitment and phosphorylation of the insulin receptor substrate 1 (IRS-1) on tyrosine residues, which in turn recruits phosphoinositide 3-kinase (PI3K) and activates Akt, a critical node of the insulin signaling pathway leading to at least the regulation of glucose uptake, glycogen synthesis, glycolysis and gluconeogenesis [2]. The activation of Akt inhibits glucose production through direct phosphorylation of transcription factors Forkhead-box Class 01 (Fox01) [3] and peroxisome proliferator-activated receptor $\gamma$ coactivator $1 \alpha$ (PGC)$1 \alpha$ [4]. Another important anabolic role of insulin is to activate fatty acid synthesis. Insulin stimulates hepatic lipogenesis by increasing the mRNA and the processed nuclear form of sterol regulatory element-binding protein-1c (SREBP-1c), a transcription factor that activates all the genes needed to produce fatty acids and triglycerides in liver [5]. Insulin-dependent SREBP-1c transcriptional regulation also requires liver X receptor (LXR) activation $[6,7]$.

Dietary proteins and amino acids (AAs) have emerged as potent modulators of insulin signaling, thereby regulating glucose and lipid metabolism. Under appropriate conditions, AAs (particularly leucine, isoleucine, alanine, and arginine) can enhance pancreatic insulin secretion and repress hepatic gluconeogenesis through the IRS-Akt-Foxo pathway [8,9]. Furthermore, AAs abundance can be sensed by mechanistic target of rapamycin complex 1 (mTORC1) [10], a crucial signaling node controlling cell growth and proliferation, which promotes de novo lipogenesis and glycolysis, through mTORC1-mediated activation of SREBP-1c and hypoxia inducible factor 1a (HIF1a), respectively [11, 12]. Moreover, excessive AAs can induce elevated activation of the mTORC1/S6K1 pathway, which elicits a negative feedback signal that hyperphosphorylates IRS- 1 at serine residues, leading to reduced IRS1 function and impaired activation of the PI3K/Akt pathway, thereby diminishing insulin action $[13,14]$. Persistent activation of mTORC1 signaling pathway may lead to insulin resistance $[14,15]$, which is defined as the inability of insulin to promote efficient glucose uptake by peripheral tissues, and commonly associated with obesity, human type 2 diabetes and nonalcoholic fatty liver disease $[16,17]$.

The p38 mitogen-activated protein kinase (MAPK) is a major kinase in the MAPK family and plays a pivotal role in regulating many essential cellular processes, such as proliferation, inflammation, differentiation, survival and migration $[18,19]$. Recent studies show that p38 MAPK also responds to key metabolic factors, thereby controlling glucose and lipid metabolism [20]. Cao et al. [21] demonstrated that activation of p38 by fasting in liver and glucagon in primary hepatocytes stimulates hepatic gluconeogenesis via regulating the phosphorylation of cAMP-response element-binding protein (CREB) and the expression of PGC1 $\alpha$. Furthermore, p38 plays an inhibitory role on hepatic lipogenesis, probably through the inhibtion of the transcription of central lipogenic genes, such as SREBP-1c and PGC$1 \beta$ [22]. However, whether nutrients regulate p38 MAPK activation, thereby regulating intermediary metabolism remains largely unknown.

Rainbow trout, like domestic cat and dolphin, exhibits relatively high dietary protein/ AAs requirement, poor utilization of dietary carbohydrates and glucose intolerant phenotype, thus it represents a relevant carnivorous model organism for the investigation of protein and glucose metabolism $[23,24]$. Furthermore, given that healthy carnivores exhibit metabolic changes after fasting or a carbohydrate rich diet that are similar to those observed in humans with diabetes, trout can be used as a comparative natural model for the study of common pathologies associated with type 2 diabetes [23]. Therefore, understanding how nutrients regulate intermediary metabolism in trout may have dual significance.

Despite the well-studied roles of protein/AAs in modulating insulin action and intermediary metabolism in mammals, relatively little is known in trout. Diets of rainbow trout generally contain more than $40 \%$ protein, which has long been suspected as a causal factor for the persistent hyperglycemia and absence of postprandial down-regulation of 
gluconeogenesis [25, 26]. In line with this hypothesis, Kirchner et al. [26] observed that low protein intake reduced hepatic gluconeogenic enzyme activities and gene expression (FBPase and G6Pase). Furthermore, in a previous study, we also demonstrated that AAs increased gluconeogenic mRNA levels (G6Pase and mPEPCK) independently of the insulin/TOR signaling pathway [27]. However, whether excessive AAs elevate hepatic gluconeogenesis via affecting insulin signaling has not been investigated in fish thus far. As for the regulation of lipogenesis, previous in vivo studies tend to indicate that dietary protein play a potent role in regulating mTOR signaling pathway [28], and lipogenic and glycolytic pathways in fish [28-30]. Moreover, our in vitro studies demonstrated that AAs (particularly leucine) together with insulin successfully stimulated the activation of mTOR signaling pathway [27, $31]$, which was proven as an upstream activator for hepatic lipogenesis in trout liver and hepatocytes [27, 32]. However, whether different AA levels affect mTORC1 activation and thereby regulating hepatic lipogenesis in fish is still unknown.

The aim of this work was to (1) study whether excessive amino acids (AAs) affect the regulation of hepatic metabolism-related gene expression and (2) determine the potential involvement of mTORC1 and p38 MAPK pathways in these regulations.

\section{Material and Methods}

\section{Animals}

Sexually immature rainbow trout (240 to $300 \mathrm{~g}$ ) were obtained from the INRA experimental fish farm facilities (INRA, Donzacq, France). Fish were maintained in tanks kept in open circuits at $18^{\circ} \mathrm{C}$ with well-aerated water under natural photoperiod conditions. Trout were fed to satiety every two days with a commercial diet (T-3P classic, Trouw, France). The experiments were carried out in accordance with the clear boundaries of EU legal frameworks, specifically those relating to the protection of animals used for scientific purposes (i.e. Directive 2010/63/EU), and under the French legislation governing the ethical treatment of animals (Decree no. 2001-464, 29 May, 2001). The investigators carrying out the experiment had "level 1" or "level 2" certification, bestowed by the Direction Départementale des Services Vétérinaires (French veterinary services) to carry out animal experiments (INRA 2002-36, 14 April, 2002).

\section{Hepatocyte Cell Culture}

Isolated liver cells were prepared as previously described [25, 27]. Cells were finally taken up in modified Hanks' medium supplemented with $1.5 \mathrm{mM} \mathrm{CaCl}_{2}, 1 \%$ defatted BSA, $3 \mathrm{mM}$ glucose, MEM essential amino acids (1X) (Invitrogen Carlsbad, California, USA), MEM non-essential amino acids (1X) (Invitrogen Carlsbad, California, USA) and antibiotic antimycotic solution (1X) (Sigma, St. Louis, MO, USA) as the basic culture medium. Cell viability ( $>98 \%$ ) was assessed using the trypan blue exclusion method $(0.04 \%$ in 0.15 $\mathrm{M} \mathrm{NaCl}$ ) and cells were counted using a haemocytometer. The hepatocyte cell suspension was plated in a six well Primaria culture dish (BD, USA) at a density of $3 \times 10^{6}$ cells / well and incubated at $18^{\circ} \mathrm{C}$. The culture medium was changed every $24 \mathrm{~h}$ over the $48 \mathrm{~h}$ of primary cell culture. Microscopic examination ensured that hepatocytes progressively re-associated throughout culture to form two-dimensional aggregates, in agreement with earlier reports [33, 34]. For the first experiment involving different amino acid levels, 48 h-cultured cells were stimulated with the mediums containing $4 \times 10^{-9} \mathrm{~mol} \mathrm{l}^{-1}$ of bovine insulin (Sigma, St. Louis, MO, USA) corresponding to the post-prandial level of insulin irrespective of dietary carbohydrate level [35], and one fold (I*1AA), two fold (I*2AA), or four fold concentrated MEM essential and non-essential amino acids mixture ( $\left.{ }^{*} 4 \mathrm{AA}\right)$, respectively, while the control cells maintained the basic culture medium (1AA but no insulin). In the second experiment, $48 \mathrm{~h}$-cultured hepatocytes were pre-incubated for $30 \mathrm{~min}$ with or without $100 \mathrm{nM}$ rapamycin (Rapa), a pharmacological TOR inhibitor. The mediums were then replaced by the medium containing $4 \times 10^{-9} \mathrm{~mol} \mathrm{l}^{-1}$ insulin and four fold concentrated MEM essential and non-essential amino acids mixture ( $\left.{ }^{*} 4 \mathrm{AA}\right)$. Cells were harvested at $45 \mathrm{~min}$ for western blot analysis or resuspended in TRIzol $^{\circledR}$ Reagent (Invitrogen, Carlsbad, CA, USA) $24 \mathrm{~h}$ after stimulation and stored at $-80^{\circ} \mathrm{C}$ for subsequent mRNA extraction. The time intervals were chosen based on the phosphorylation peaks of TOR signaling pathway or relevant metabolic gene expression peaks, respectively (data not shown). 


\section{Cellular Physiology Cell Physiol Biochem 2015;36:1084-1100 \begin{tabular}{ll|l} 
DOI: 10.1159/000430281 & $\begin{array}{l}\text { () 2015 S. Karger AG, Basel } \\
\text { www.karger.com/cpb }\end{array}$ \\
\hline
\end{tabular}}

\section{Protein extraction and Western blotting}

At the end of the stimulation period, cells were carefully washed with two times $1 \mathrm{ml}$ of cold phosphate buffered saline (PBS). Then $300 \mu \mathrm{l}$ of cell lysis buffer [36] were added before being stored the culture dish at $-80^{\circ} \mathrm{C}$ overnight. Then cells were scraped, collected, and lysed on ice for $30 \mathrm{~min}$. Lysates were centrifuged at $12.000 \mathrm{~g}$ for $30 \mathrm{~min}$ at $4^{\circ} \mathrm{C}$. The resulting supernatant fractions were recovered and stored at $-80^{\circ} \mathrm{C}$. Protein concentrations were determined using the Bio-Rad protein assay kit (Bio-Rad Laboratories, Munich, Germany) with BSA as standard. Lysates (2 $\mu \mathrm{g}$ of total protein per lane for Akt/S6/4EBP1, $7 \mu \mathrm{g}$ for TOR/ S6K1/p38 MAPK and $17 \mu$ for IRS-1, respectively) were subjected to SDS-PAGE and Western blotting using the appropriate antibodies. Anti-phospho-Akt (Ser ${ }^{473}$ ) (no. 9271), anti-phospho-Akt ( $\mathrm{Thr}^{308}$ ) (no. 9275), anti-carboxyl terminal Akt (no. 9272), anti-phospho-TOR ( $\operatorname{Ser}^{2448}$ ) (no. 2971), anti-TOR (no. 2972), antiphospho-S6 protein kinase 1 ( $\mathrm{Thr}^{389}$ ) (no. 9205), anti-S6 protein kinase 1 (no. 9202), anti-phospho-S6 (Ser ${ }^{235 / 236}$ ) (no. 4856), anti-S6 (no. 2217), anti-phospho-4E-BP1 (Thr ${ }^{37 / 46}$ ) (no. 9459), anti-4E-BP1 (no. 9452), anti-phospho-IRS-1 (Ser ${ }^{302}$ ) (no. 2384), anti-phospho-p38 MAPK (no. 9211) and anti- $\beta$-Tubulin (no. 2146) were purchased from Cell Signaling Technologies (Ozyme, Saint Quentin Yvelines, France). Anti-p38 MAPK (no. sc-535) was purchased from Santa Cruz Biotechnology (Dallas, Texas, USA). All of these antibodies (except anti-phospho-IRS-1 (Ser ${ }^{302}$ ), anti-phospho-p38 MAPK and anti-p38 MAPK) were successfully crossreacted with rainbow trout [32]. For anti-phospho-IRS-1 (Ser ${ }^{302}$ ), anti-phospho-p38 MAPK and anti-p38 MAPK antibody, the molecular weight and amino acid sequences were monitored in the SIGENAE database [37] to check for a good conservation of the antigen sequence. After washing, membranes were incubated with an IRDye Infrared secondary antibody (LI-COR Biosciences, Lincoln, NE, USA). Bands were visualized by Infrared Fluorescence using the Odyssey Imaging System (LI-COR Biosciences) and quantified by Odyssey Infrared imaging system software (Version 3.0, LI-COR Biosciences).

\section{Gene expression analysis}

Total RNA samples were extracted from hepatocytes using TRIzol ${ }^{\circledR}$ Reagent (Invitrogen, Carlsbad, CA, USA) according to the manufacturer's recommendations, quantified by spectrophotometry (absorbance at $260 \mathrm{~nm}$ ) and its integrity was assessed using Agarose Gel Electrophoresis. A $1 \mu \mathrm{g}$ sample of the resulting total RNA was reverse transcribed into cDNA using the SuperScript ${ }^{\mathrm{TM}}$ III Reverse Transcriptase kit (Invitrogen, Carlsbad, CA, USA) and random primers (Promega, Charbonniéres, France) according to the manufacturers' instructions. Target gene expression abundance was determined by quantitative realtime (q) RT-PCR, using specific primers [38-42]. Primers targeting alanine transaminase 2 (forward: TGGGTGCGTACAGTGCCAGT; reverse: GACGCACCCTCACCACACAC; Sigenae AU081029.s.om.10), aspartate transaminase 1 (forward: TCAAGAGTGGCAGGAACATCA; reverse: AGCGTCTCTGAAGATGGGTGT; Sigenae CA359859.s.om.10), aspartate transaminase 2 (forward: TCTGTGCCCAGTCCTTCTC; reverse: GGAGGGTTGGACCAGGT; Sigenae CA344854.s.om.10.) and branched-chain $\alpha$-ketoacid dehydrogenase $\alpha$ subunit (forward: TCGCTGTGTACAACGCTACC; reverse: GCCTCCATCACCATCTTGC) were newly designed using Primer3 software. To confirm specificity, amplicons were purified and sequenced (Beckman Coulter Genomics, UK).

qRT-PCR was performed as previously described [36]. Quantitative RT-PCR analyses were focused on several key enzymes of hepatic metabolism, which were glucokinase (GK; EC 2.7.1.2), 6-phosphofructo-1kinase (6PF1K; EC 2.7.1.11), pyruvate kinase (PK; EC 2.7.1.40) and transcription factor hypoxia-inducible factor 1-alpha (HIF-1 $\alpha$ ) for glycolysis; glucose transporter 2 (GLUT2) for glucose transport ; glucose-6phosphatase (G6Pase; EC 3.1.3.9) for glucose dephosphorylation; fructose-1,6-bisphosphatase (FBPase; EC 3.1.3.11) and phosphoenolpyruvate carboxykinase (PEPCK; EC 4.1.1.32) for gluconeogenesis; ATP citrate lyase (ACLY; EC 2.3.3.8) and fatty acid synthase (FAS; EC 2.3.1.85) for lipogenesis; glucose-6-phosphate dehydrogenase (G6PDH; EC 1.1.1.49) for pentose phosphate shunt; $\Delta 6$ fatty acyl desaturase (D6D; EC 1.14.19.3), Stearoyl-CoA desaturase-1 (SCD1 or D9D; EC 1.14.19.1), elongation of very long chain fatty acids like-5 (Elovl5; EC 2.3.1.199) and elongation of very long chain fatty acids like-2 (Elovl2; EC 2.3.1.199) for fatty acid bioconversion, and two relevant transcription factors sterol regulatory element binding protein 1-like (SREBP1C) and liver X receptor (LXR); serine dehydratase (SD; EC:4.3.1.17), alanine transaminase (ALAT; EC 2.6.1.2), aspartate transaminase (ASAT; EC 2.6.1.1), branched-chain $\alpha$-ketoacid dehydrogenase (BCKD; EC 1.2.4.4) and branched-chain $\alpha$-ketoacid dehydrogenase kinase (BCKDK; EC 2.7.11.4) for amino acid catabolism. When different isoforms of a gene were known in rainbow trout (as for G6Pase), gene expression analysis was performed on each isoform. Elongation factor-1alpha (EF1 $\alpha$ ) was employed as 
a non-regulated reference gene, as previously used in rainbow trout and it was stably expressed in our investigations (data not shown).

\section{Statistical analysis}

The results of western blot $(N=4)$ and gene expression $(N=6)$ are expressed as means + s.e.m. and were analyzed using one-way ANOVA, followed by a Tukey test. In cases where data were nonparametric or not homoscedastic, data transformations, such as logarithms, square roots and reciprocals, were used to meet ANOVA criteria. Normality was assessed using the Shaprio-Wilk test, while homoscedasticity was determined using Levene's test. For all statistical analyses, the level of significance was set at $P<0.05$.

\section{Results}

Amino acid levels affected the phosphorylation of Akt/TOR signaling pathway

First, we investigated whether the phosphorylation of Akt/TOR signaling pathway was affected by different amino acid levels (Fig. 1).

As expected, I*1AA treated cells showed higher Akt (on $\mathrm{Thr}^{308}$ and Ser ${ }^{473}$ ), S6K1 and S6 phosphorylation levels compared to control cells, indicating that insulin effectively triggered

Fig. 1. Effects of different amino acid levels on the phosphorylation of (A) Akt Ser ${ }^{473}$, (B) Akt $\mathrm{Thr}^{308}$, (C) S6K1, (D) S6, (E) IRS$1 \mathrm{Ser}^{302}$ and (F) p38 MAPK protein in trout hepatocytes. The experiment was conducted in 48 h-cultured trout hepatocytes. Cells were then stimulated for 45 min with the mediums containing $4 \times 10^{-9} \mathrm{~mol} \mathrm{l}^{-1}$ insulin (I), and one fold (I*1AA), two fold (I*2AA), or four fold concentrated amino acids (I*4AA), respectively, while the control cells maintained the basic culture medium (1AA but no insulin). Gels were loaded with $2 \mu \mathrm{g}$ of total protein per lane for Akt/S6, $7 \mu \mathrm{g}$ for S6K1/p38 MAPK and $17 \mu$ g for IRS-1, respectively. A representative blot is shown. Results are means + s.e.m. $(N=4)$ and were analyzed using one-way ANOVA, followed by a Tukey test. Values with different superscript letters are significantly different at $P<0.05$.

\section{A}
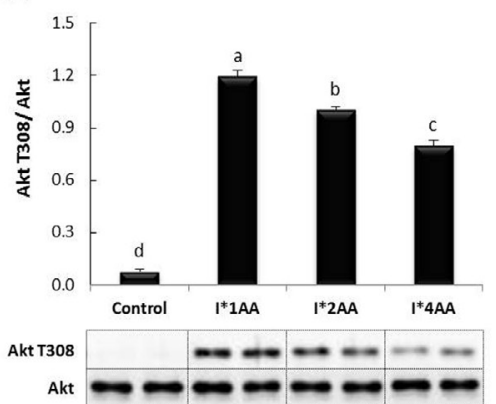

C

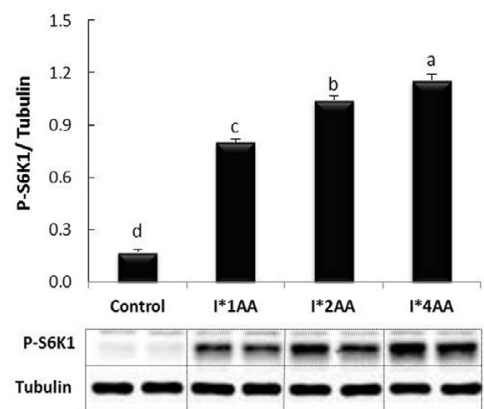

E

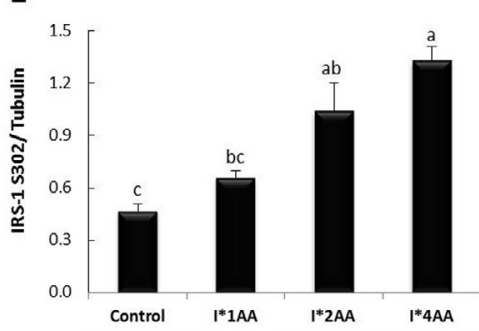

IRS-1 S302

Tubulin
B

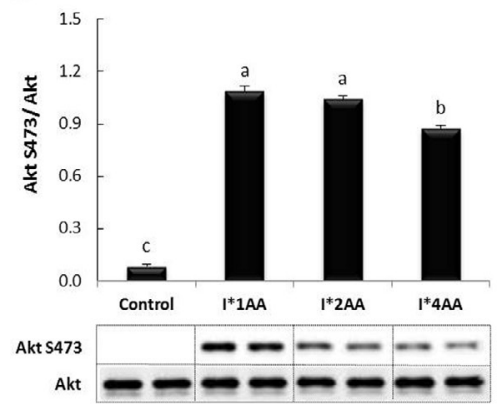

D

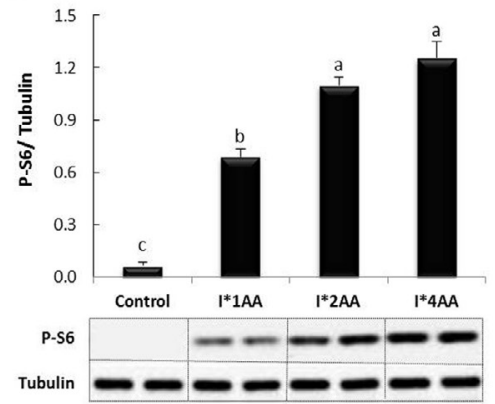

F

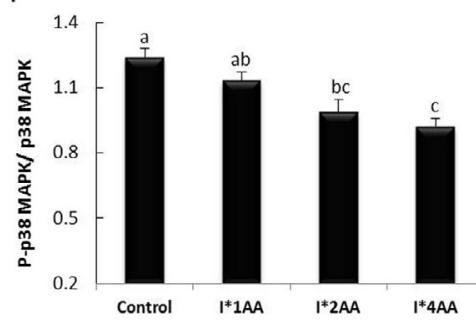

P-p38MAPK $-\ldots+\cdots$ P38MAPK $-\infty-\infty$ 


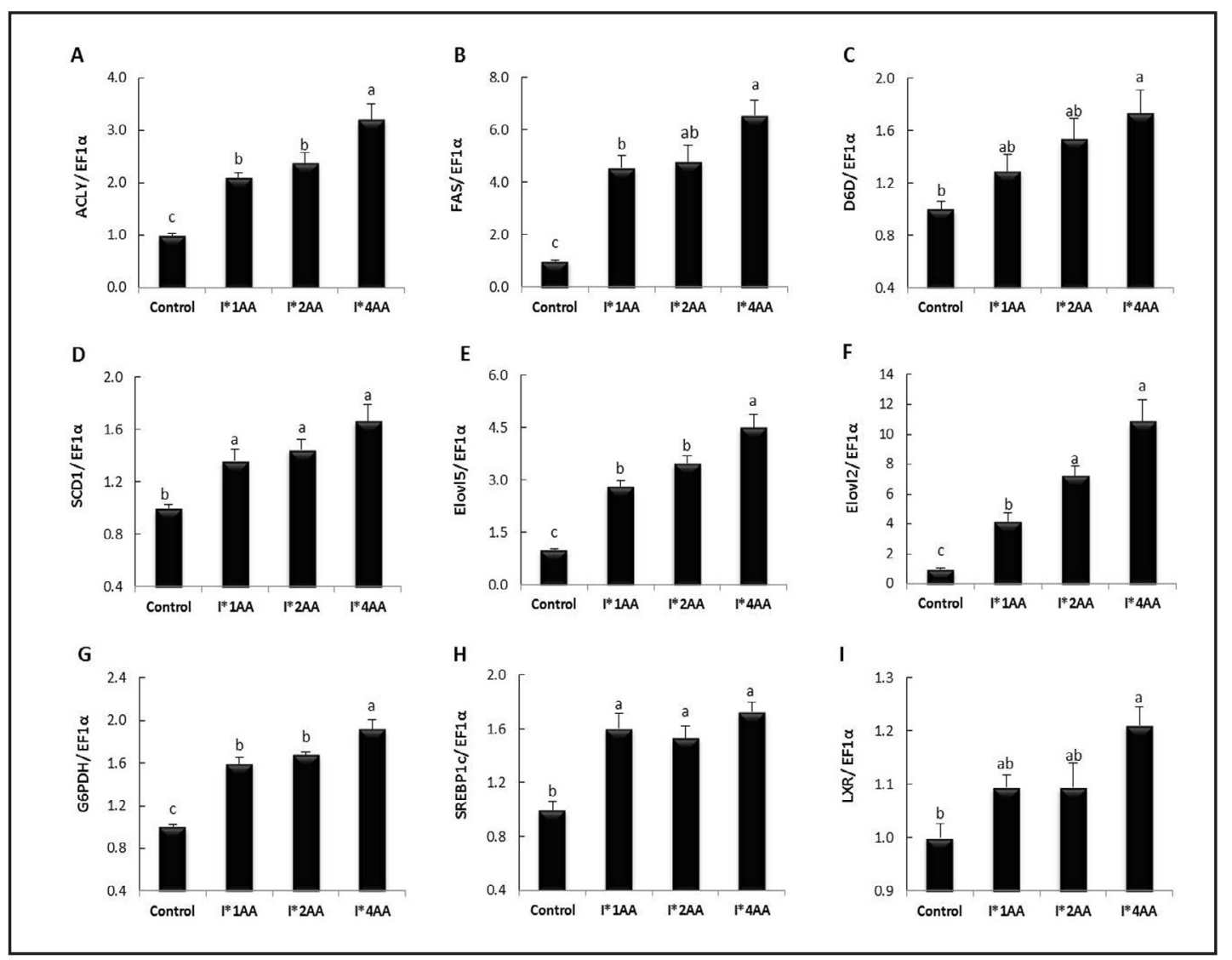

Fig. 2. Effects of different amino acid levels on the regulation of fatty acid biosynthetic gene expression in trout hepatocytes. mRNA levels of genes involved in de novo lipogenesis including (A) ACLY and (B) FAS, fatty acid bioconversion including (C) D6D, (D) SCD1, (E) Elovl5 and (F) Elovl2, NADPH production including (G) G6PDH, and relevant transcriptional factors (H) SREBP1c and (I) LXR in the primary hepatocytes of rainbow trout after $24 \mathrm{~h}$ stimulation. The experiment was conducted in $48 \mathrm{~h}$-cultured trout hepatocytes. Cells were then stimulated with the mediums containing $4 \times 10^{-9} \mathrm{~mol} \mathrm{l}^{-1}$ insulin (I), and one fold (I*1AA), two fold $\left(I^{*} 2 \mathrm{AA}\right)$, or four fold concentrated amino acids ( $\left.\mathrm{I}^{*} 4 \mathrm{AA}\right)$, respectively, while the control cells maintained the basic culture medium (1AA but no insulin). Expression values are first normalized with elongation factor-1 alpha (EF1 $\alpha$ )-expressed transcripts then further normalized to the levels of control hepatocytes. Results are means + s.e.m. $(N=6)$ and were analyzed using one-way ANOVA, followed by a Tukey test. Values with different superscript letters are significantly different at $P<0.05$.

the activation of Akt/TOR signaling pathway as previously demonstrated [27]. Of note, the phosphorylation of IRS-1 on Ser302 and p38 MAPK was not affected by the addition of insulin in 1AA treated cells.

Increased amino acid levels gradually enhanced S6K1 phosphorylation (Fig. 1C). Furthermore, phosphorylated S6 in I*2AA and I*4AA treated cells was also higher compared to I*1AA treated cells (Fig. 1D). In contrast, increased amino acid levels gradually decreased Akt phosphorylation on $\mathrm{Thr}^{308}$ (Fig. 1A) and the phosphorylation of Akt on $\mathrm{Ser}^{473}$ in I*4AA treated cells was significantly lower than in I*1AA or I*2AA treated cells (Fig. 1B). Because the phosphorylation of IRS-1 on serine residues is known as a potential link between TOR/ S6K1 and Akt protein phosphorylation in mammals, we further studied the phosphorylation of IRS-1 on Ser ${ }^{302}$ and found that phosphorylated IRS-1 on Ser ${ }^{302}$ in I*4AA treated cells was significantly higher than in I*1AA treated cells (Fig. 1E). Moreover, the phosphorylation of p38 MAPK in I*4AA treated cells was markedly lower compared to I*1AA treated cells (Fig. 1F).

\section{KARGER}




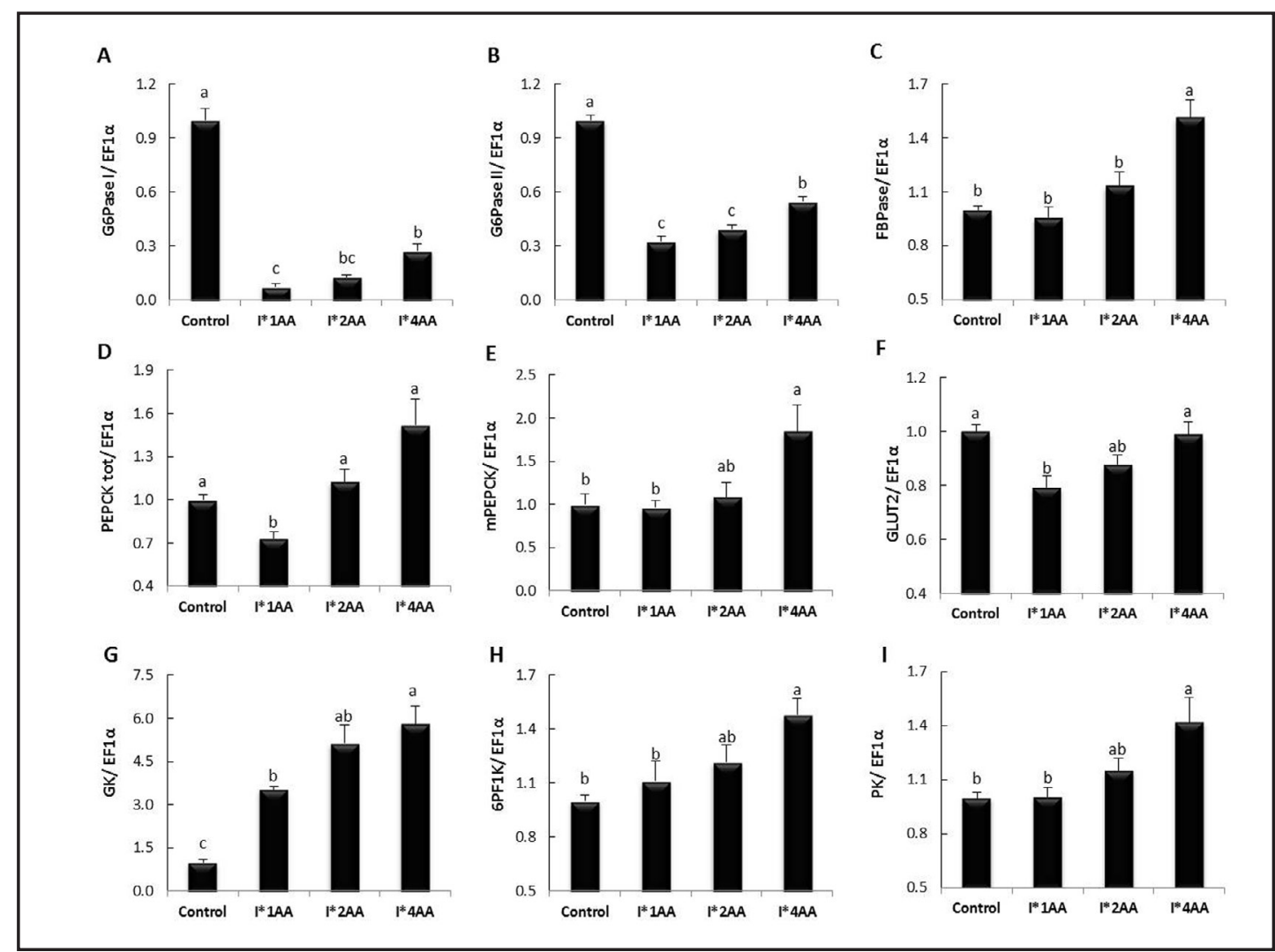

Fig. 3. Effects of different amino acid levels on the regulation of glucose metabolism-related gene expression in trout hepatocytes. mRNA levels of genes involved in gluconeogenesis including (A) G6Pase I, (B) G6Pase II, (C) FBPase, (D) PEPCKtot and (E) mPEPCK, glucose transport including (F) GLUT2, and glycolysis including (G) GK, (H) 6PF1K and (I) PK in the primary hepatocytes of rainbow trout after 24 h stimulation. The experiment was conducted in $48 \mathrm{~h}$-cultured trout hepatocytes. Cells were then stimulated with the mediums containing $4 \times 10^{-9} \mathrm{~mol} \mathrm{l}^{-1}$ insulin (I), and one fold (I*1AA), two fold (I*2AA), or four fold concentrated amino acids ( $\left.\mathrm{I}^{*} 4 \mathrm{AA}\right)$, respectively, while the control cells maintained the basic culture medium (1AA but no insulin). Expression values are first normalized with elongation factor- 1 alpha (EF1 $\alpha$ )-expressed transcripts then further normalized to the levels of control hepatocytes. Results are means + s.e.m. $(N=6)$ and were analyzed using one-way ANOVA, followed by a Tukey test. Values with different superscript letters are significantly different at $P<0.05$.

Fatty acid biosynthetic gene expression was up-regulated by high level of AAs

We further investigated the effects of different amino acid levels on the regulation of fatty acid biosynthetic gene expression in trout hepatocytes (Fig. 2).

Except D6D (Fig. 2C) and LXR (Fig. 2I), all the examined mRNA levels of the key enzymes involved in de novo lipid synthesis including ACLY, FAS, SCD1, Elovl5, Elovl2 and G6PDH, and SREBP1c, a transcription factor that activates de novo lipogenesis, were all significantly upregulated in I*1AA treated cells compared to control cells, indicating that insulin significantly up-regulated fatty acid biosynthetic gene expression in trout hepatocytes, which is consistent with previous demonstrations in trout [27, 43] and mammals [44].

Moreover, mRNA levels of the key enzymes involved in de novo lipogenesis, including ACLY (Fig. 2A) and FAS (Fig. 2B), fatty acid bioconversion including Elovl5 (Fig. 2E) and Elovl2 (Fig. 2F), and NADPH production including G6PDH (Fig. 2G) were all significantly higher in $I^{*} 4 \mathrm{AA}$ treated cells than in I*1AA treated cells. Furthermore, similar enhancements were also observed between I*2AA and I*4AA treated cells for the mRNA levels of ACLY (Fig. 2A), Elovl5 (Fig. 2E) and G6PDH (Fig. 2G). Of note, despite no significant difference was observed

\section{KARGER}


Fig. 4. Effects of different amino acid levels on the regulation of amino acid catabolic gene expression in trout hepatocytes. mRNA levels of genes involved in amino acid catabolism including (A) SD, (B) ALAT2, (C) ASAT1, (D) ASAT2, (E) BCKDE1 $\alpha$, (F) BCKDE2 and (G) BCKDK in the primary hepatocytes of rainbow trout after $24 \mathrm{~h}$ stimulation. The experiment was conducted in 48 h-cultured trout hepatocytes. Cells were then stimulated with the mediums containing $4 \times 10^{-9}$ mol $\mathrm{l}^{-1}$ insulin (I), and one fold (I*1AA), two fold (I*2AA), or four fold concentrated amino acids (I*4AA), respectively, while the control cells maintained the basic culture medium (1AA but no insulin). Expression values are first normalized with elongation factor-1 alpha (EF1 $\alpha$ )expressed transcripts then further normalized to the levels of control hepatocytes. Results are means + s.e.m. $(N=6)$
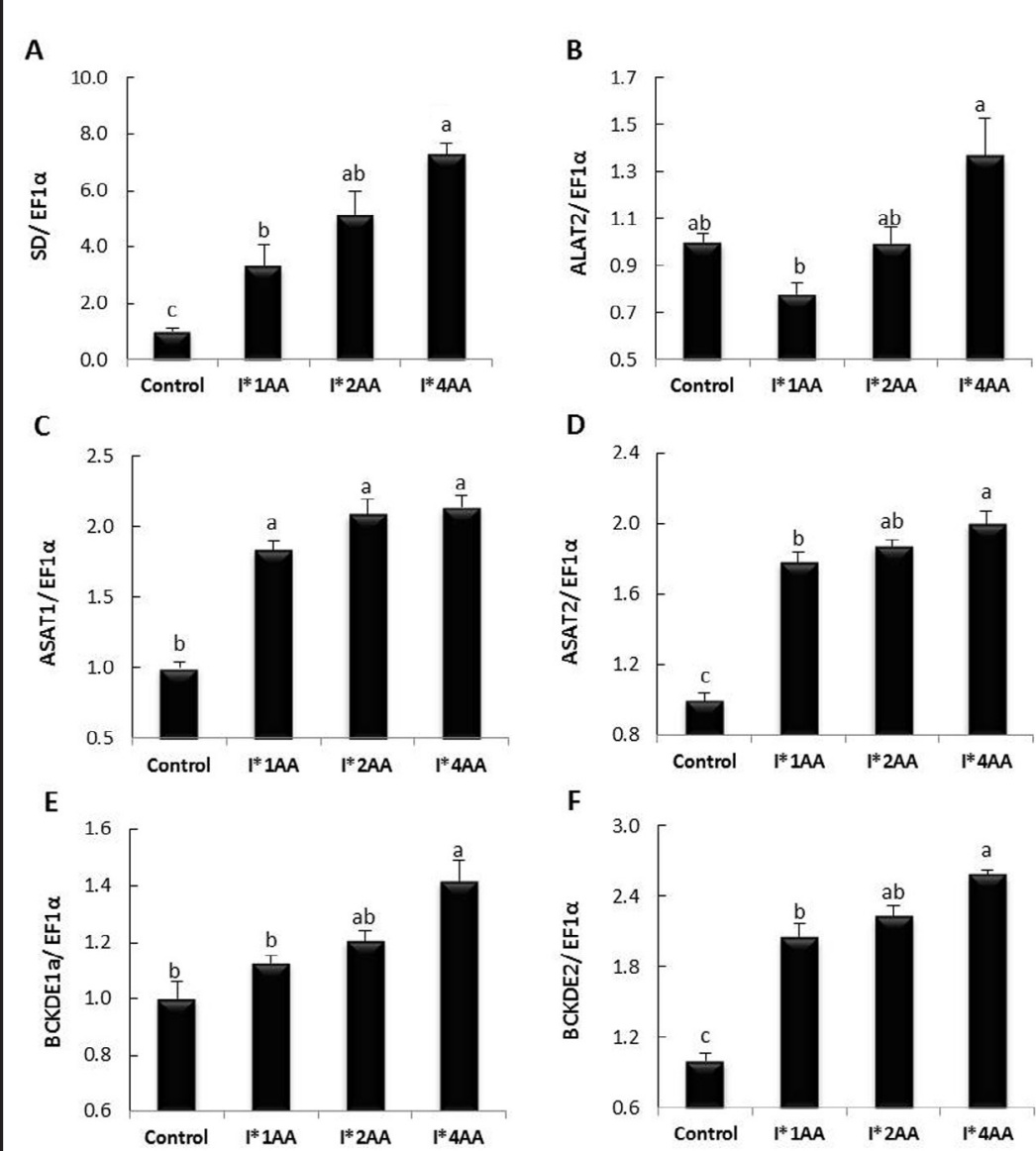

D
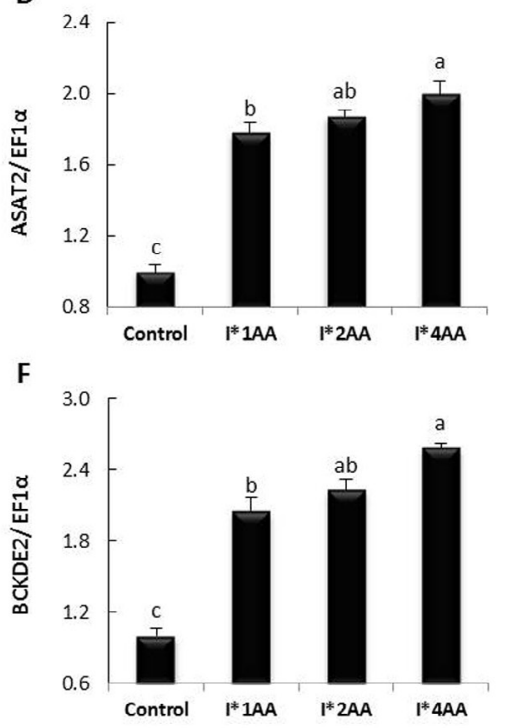

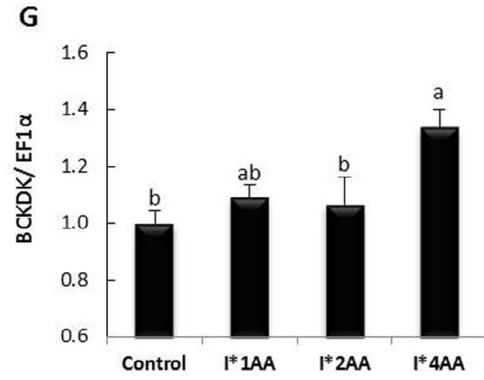

and were analyzed using one-way ANOVA, followed by a Tukey test. Values with different superscript letters are significantly different at $P<0.05$.

for the mRNA levels of D6D (Fig. 2C), SCD1 (Fig. 2D) or LXR (Fig. 2I), they all exhibited similar patterns as the other examined fatty acid biosynthetic genes, which were positively regulated by increased amino acid levels.

High level of AAs up-regulated gluconeogenic and glycolytic gene expression

We also investigated the effects of different amino acid levels on the regulation of gluconeogenic and glycolytic gene expression in trout hepatocytes (Fig. 3). The addition of insulin significantly decreased the mRNA levels of G6Pase I (Fig. 3A), G6Pase II (Fig. 3B), PEPCKtot (Fig. 3D) and GLUT2 (Fig. 3F), and significantly increased GK mRNA level (Fig. 3G), while no significant variations was observed for the mRNA levels of FBPase (Fig. 3C), mPEPCK (Fig. 3E), 6PF1K (Fig. 3H) and PK (Fig. 3I). Messenger RNA levels of the key enzymes involved in gluconeogenesis (G6Pase I, G6Pase II, FBPase, PEPCKtot and mPEPCK), 
Fig. 5. Effects of mTORC1 overactivation (I*4AA) and inhibition (I*4AA+Rapa) on the phosphorylation of Akt Ser ${ }^{473}$, Akt Thr ${ }^{308}$, TOR, S6K1, S6, 4E-BP1, IRS-1 Ser ${ }^{302}$ and p38 MAPK protein in trout hepatocytes. Cells were preincubated for $30 \mathrm{~min}$ with or without $100 \mathrm{nM}$ rapamycin (Rapa), a TOR inhibitor. The culture medium was then replaced for $45 \mathrm{~min}$ by the medium containing $4 \times 10^{-9} \mathrm{~mol} \mathrm{l}^{-1}$ insulin (I) and four fold concentrated amino acids (I*4AA). Gels were loaded with $2 \mu \mathrm{g}$ of total protein per lane for Akt/S6/4EBP1, $7 \mu \mathrm{g}$ for TOR/S6K1/p38 MAPK and $17 \mu \mathrm{g}$ for IRS-1, respectively. Western blots were performed on four individual samples and similar results were obtained. This figure includes representative blots.

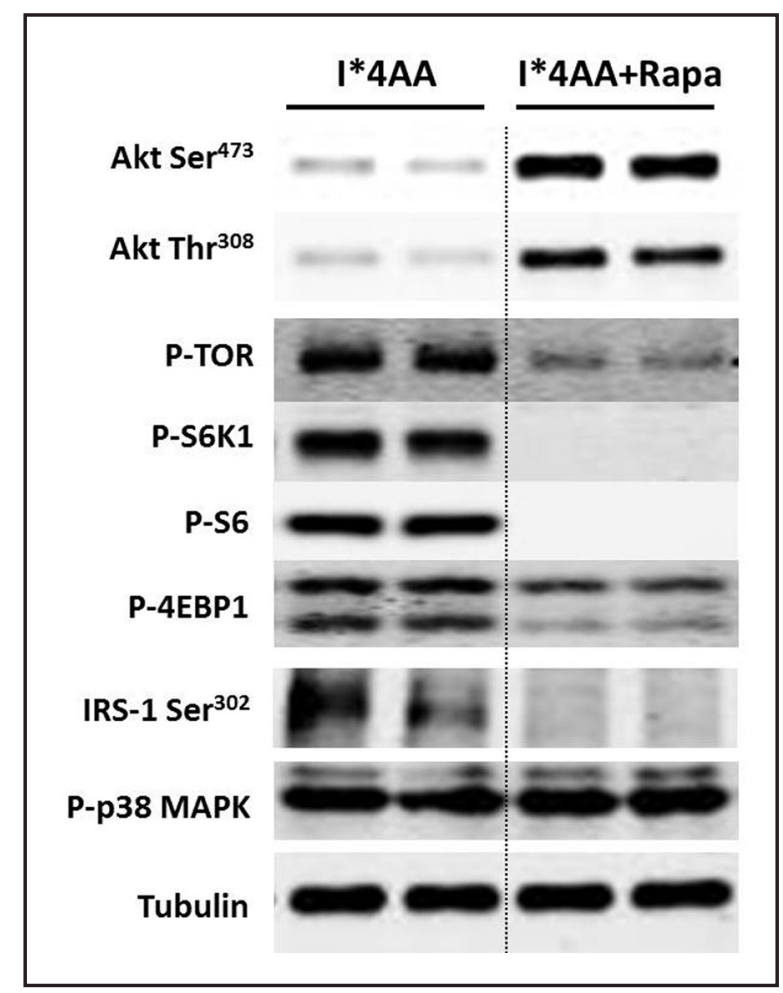

glucose transporter (GLUT2), and glycolysis (GK, 6PF1K and PK) were all significantly higher in I*4AA treated cells than in I*1AA treated cells, indicating that high level AAs up-regulated gluconeogenic and glycolytic gene expression.

High level of AAs up-regulated AA catabolic gene expression

As shown in Fig.4, the addition of insulin upregulated the mRNA levels of SD (Fig. 4A), ASAT1 (Fig. 4C), ASAT2 (Fig. 4D) and BCKDE2 (Fig. 4F), while no changes for the mRNA levels of ALAT2 (Fig. 4B), BCKDE1 $\alpha$ (Fig. 4E) and BCKDK (Fig. 4G). Despite no modulation for ASAT1, messenger RNA levels of SD, ALAT2, ASAT2, BCKDE1 $\alpha$ and BCKDE2 were all significantly higher in I*4AA treated cells compared to I*1AA treated cells, and BCKDK increased in I*4AA treated cells compared to I*2AA treated cells, indicating that high level AAs up-regulated AA catabolic gene expression.

Excessive AAs decreased Akt phosphorylation through mTORC1-dependent manner

In order to investigate whether excessive AAs reduced Akt phosphorylation through mTORC1/S6K1-induced negative feedback loop involving the phosphorylation of IRS-1 on serine residues, we further treated trout hepatocytes with I*4AA in the presence or absence of rapamycin.

As expected, rapamycin partially inhibited the phosphorylation of TOR and 4E-BP1 and totally abolished the phosphorylation of S6K1 and S6 as previously observed [27, 32]. More importantly, we observed that rapamycin significantly inhibited the phosphorylation of IRS1 on $\mathrm{Ser}^{302}$ and strongly increased the Akt phosphorylation (on $\mathrm{Thr}^{308}$ and $\mathrm{Ser}^{473}$ ) (Fig. 5). p38 phosphorylation was not affected by rapamycin, indicating that the phosphorylation of p38 MAPK is mTORC1-independent, which is compatible with previous demonstration [45].

Inhibition of mTORC1 activation resulted in suppressed fatty acid biosynthetic and gluconeogenic gene expression

We further examined the effects of mTORC1 overactivation and inhibition on the regulation of fatty acid biosynthetic, gluconeogenic, glycolytic and AA catabolic gene expression in trout hepatocytes. Messenger RNA levels of the key enzymes involved in de

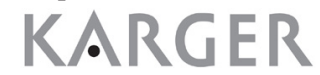


Fig. 6. Effects of mTORC1 overactivation $\left(I^{*} 4 \mathrm{AA}\right)$ and inhibition (I*4AA+Rapa) on the regulation of fatty acid biosynthetic, gluconeogenic and glycolytic gene expression in trout hepatocytes. (A) mRNA levels of genes involved in de novo lipid synthesis including ACLY, FAS, D6D, SCD1, Elovl5, Elovl2, G6PDH, SREBP1c and LXR; (B) mRNA levels of genes involved in gluconeogenesis including G6Pase I, G6Pase II, FBPase, PEPCKtot and mPEPCK, glucose transport GLUT2, and glycolysis including GK, 6PF1K, PK and HIF1- $\alpha$; (C) mRNA levels of genes involved in amino acid catabolism including SD, ALAT2, ASAT1, ASAT2, BCKDE1 $\alpha$, BCKDE2 and BCKDK, in the primary hepatocytes of rainbow trout after $24 \mathrm{~h}$ stimulation. Cells were pre-incubated for $30 \mathrm{~min}$ with or without $100 \mathrm{nM}$ rapamycin (Rapa), then stimulated with the medium containing $4 \times 10^{-9} \mathrm{~mol} \mathrm{l}^{-1}$ insulin (I) and four fold concentrated amino acids (I*4AA) for $24 \mathrm{~h}$. Expression values are first normalized with elongation factor-1 alpha $(\mathrm{EF} 1 \alpha)$ expressed transcripts then further normalized to the lev-
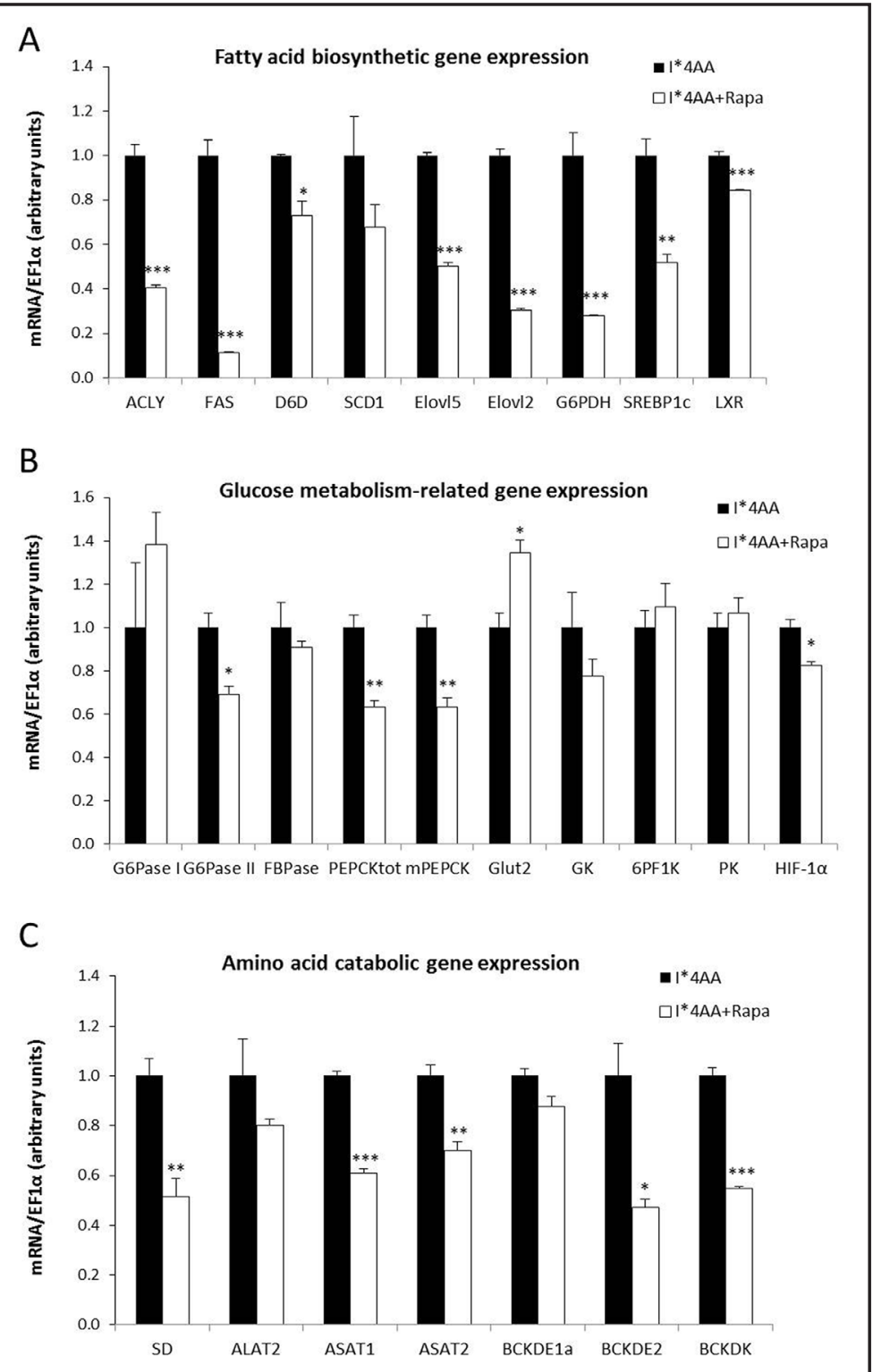
els of I*4AA hepatocytes $(N=6)$. “*” indicates significant difference at $P<0.05$, “**”indicates $P<0.01$, “***”indicates $P<0.001$.

novo lipid synthesis (ACLY, FAS, D6D, Elovl5, Elovl2 and G6PDH), gluconeogenesis (G6Pase II, PEPCKtot and mPEPCK) and amino acid catabolism (SD, ASAT1, ASAT2, BCKDE2 and BCKDK) were all significantly reduced by rapamycin (Fig. 6A, 6B and 6C). In addition, three transcription factors, SREBP1c and LXR for activating de novo lipid synthesis, and HIF-1 $\alpha$ for regulating glycolysis, were significantly reduced by rapamycin (Fig. 6A and 6B). Messenger RNA levels of SCD1, G6Pase I, FBPase, GK, 6PF1K, PK, ALAT2 and BCKDE1 $\alpha$ were not significantly affected by rapamycin.

\section{Discussion}

Rainbow trout, like the other carnivorous animals consumes diets with relatively high protein content compared to humans, rodents and other terrestrial domestic animals 
$[23,46]$. Presumably, ingested protein/AAs not only regulate protein metabolism, but also modulate glucose and lipid metabolism. The current studies were designed to evaluate the effects of different AA levels on the regulation of hepatic fatty acid biosynthetic, glucose metabolism-related and amino acid catabolic gene expression, and also to assess the potential involvements of Akt/mTORC1 and p38 MAPK signaling pathway in these regulation processes using freshly isolated trout hepatocytes. We demonstrated that high levels of AAs up-regulate hepatic fatty acid biosynthetic gene expression through an mTORC1-dependent manner, while attenuating insulin-mediated down-regulation of gluconeogenesis through elevated IRS-1 phosphorylation on $\mathrm{Ser}^{302}$, which in turn impairs the activation of Akt pathway and insulin action.

\section{AAs modulated insulin signaling and gluconeogenesis}

Our first effort revealed that high levels of AAs attenuated insulin/Akt signaling through mTORC1/S6K1-induced feedback loop in rainbow trout hepatocytes. Increased AA levels not only elevated the phosphorylation of mTORC1 downstream effectors, S6K1 and S6, but also enhanced the phosphorylation of IRS-1 on Ser $^{302}$ and decreased the phosphorylation of Akt on both $\mathrm{Ser}^{473}$ and $\mathrm{Thr}^{308}$. Given that IRS-1 Ser ${ }^{302}$ phosphorylation is known as a direct target of mTORC1 and S6K1 in mammals $[14,47]$, which disrupts the ability of the phosphotyrosinebinding domain to interact with activated insulin receptor, thereby decreasing insulin signaling [48], we first inferred that high levels of AAs enhanced IRS-1 Ser ${ }^{302}$ phosphorylation and repressed Akt phosphorylation through mTORC1/S6K1-induced feedback loop. By using rapamycin, we further demonstrated that mTORC1 inhibition blunted IRS-1 Ser ${ }^{302}$ phosphorylation and restored Akt phosphorylation in excessive (four fold concentrated) AAs-treated hepatocytes, confirming the existence of mTORC1/S6K1-operated negative feedback loop decreasing insulin sensitivity under AAs excess conditions in trout. Therefore, we indeed demonstrated that increased AA levels promoted mTORC1/S6K1 activation, which in turn operated a negative feedback loop toward Akt signaling pathway through, at least in part, enhanced IRS-1 phosphorylation on $\mathrm{Ser}^{302}$. This demonstration is in agreement with previous in vitro [49-51] and in vivo [52,53] mammalian investigations.

An intriguing finding of the present study is that high levels of AAs elevated hepatic gluconeogenic gene expression through attenuating insulin signaling. Consistent with previous demonstrations in trout $[25,27]$, insulin effectively suppressed the gene expression of two key gluconeogenic enzymes, G6Pase and PEPCK. However, increased AA levels attenuated these suppressions and increased the gene expression of FBPase, suggesting that insulin-mediated down-regulation of hepatic gluconeogenesis was attenuated by increased AA sufficiency. This finding is in agreement with previous in vivo findings in trout and sea bass, which reported that higher hepatic gluconeogenic enzyme activities and/or mRNA levels were associated with high dietary protein diet/intake compared to low protein diet/ intake [26, 54-58]. Furthermore, the negative relation between Akt phosphorylation and gene expression of G6Pase and PEPCK was consistently observed in all the insulin-, different AA levels- and rapamycin-mediated modulations, indicating that hepatic gluconeogenesis was negatively controlled by Akt phosphorylation in trout hepatocytes, as in mammals $[2,59]$. Therefore, we concluded that high levels of AAs attenuated insulin-mediated down-regulation of hepatic gluconeogenic gene expression through mTORC1/S6K1induced feedback loop toward Akt pathway. Similar inhibitory effects on insulin action as a consequence of increased AA supply have also been reported in mammalian hepatocytes $[50,60]$, muscle cells [49] and adipocytes [51, 61, 62], as well as in vivo studies [53, 63, 64]. The present work together with previous study [27] provides strong evidences that increased AA sufficiency up-regulates hepatic gluconeogenesis through insulin/TOR-independent manner(s) and as well as impairing insulin action. However further studies are needed to test whether AAs (particularly glutamine) also promote glucose production through stimulating hexosamine biosynthetic pathway/O-GlcNAc signaling [65]. Furthermore, considering that persistent activation of mTORC1 and S6K1 may promote insulin resistance and glucose intolerance $[13,15]$, our finding, that high levels of AAs up-regulated hepatic

\section{KARGER}


gluconeogenic gene expression through attenuating insulin signaling, indeed highlighted the potential role of AAs as an inducer for insulin resistance and impaired glucose homeostasis in carnivorous species such as salmonids. However, it is noteworthy that AAs elevation in vivo can also stimulate higher insulin secretion $[66,67]$, which may counteract the effects of AAs on glucose production [53]. Thus, whether high protein diet/intake modulates insulin action and glucose production in vivo still needs to be investigated in fish.

\section{AAs regulated fatty acid biosynthesis and glycolysis}

Impaired insulin signaling by high levels of AAs partially lost its ability to inhibit hepatic gluconeogenesis, yet it retained its ability to promote fatty acid biosynthesis. mTORC1 inhibition by rapamycin markedly suppressed the expression of genes involved in de novo lipogenesis (ACLY and FAS), fatty acid bioconversion (D6D, Elovl5 and Elovl2), NADPH production (G6PDH), and transcriptional factors SREBP1c and LXR, confirming that mTORC1 signaling is essential to stimulate specific metabolic pathways, including de novo lipogenesis, fatty acid bioconversion and the oxidative arm of the pentose phosphate pathway (PPP), which is consistent with previous demonstration in mammals [68]. Furthermore, we observed that enhanced gene expression of ACLY, FAS, Elovl5, Elovl2 and G6PDH by high levels of AAs, was also associated with enhanced mTORC1 activation. Therefore, we concluded that increased AA levels up-regulated fatty acid biosynthetic gene expression through an mTORC1dependent manner. This conclusion is consistent with previous findings in trout $[27,32,39]$, which showed that mTOR activation is positively related to elevated lipogenic mRNA levels and/or enzyme activities. The results are also consistent with the findings in mammals [69, 70] and in fish [28-30], showing that high protein diets induced higher fatty acid synthetic gene expression and/or enzyme activities compared to low protein diets. In contrast, all of these results differ from the in vitro findings of Allee et al. [71] and Rosebrough et al. [72], who observed that lipogenesis and malic enzyme activity were inversely related to dietary protein levels. Part of these discrepancies may be ascribed to species/tissue specificity or varied protein levels. mTORC1 activation regulates fatty acid biosynthetic gene expression probably through the transcription factors, SREBP1c and LXR [6]. Whereas insulin and amino acids effectively enhanced the expression of SREBP1c and LXR, we failed to demonstrate their AAs-induced changes at the transcriptional level. Given that both SREBP1c and LXR can be regulated transcriptionally and posttranscriptionally $[73,74]$, we presume that in trout hepatocytes high levels of AAs contribute to the posttranscriptional regulation of SREBP1c and LXR, probably through posttranslational modifications including phosphorylation, ubiquitinylation, and acetylation.

Increased AA availability also elevated glycolytic gene expression. GK, also known as hexokinase IV, plays a pivotal role in blood glucose homeostasis by catalyzing the phosphorylation of glucose, providing metabolites for glycolysis, glycogenesis and pentose phosphate pathway in hepatocytes [75]. We observed that insulin significantly up-regulated GK mRNA level in trout hepatocytes, which is consistent with the previous demonstrations in fish [25, 27, 76] and mammals [77-79] but differs from other studies based on intraperitoneal administration of insulin in trout $[80,81]$. GK and the other two glycolytic genes, 6PF1K and PK, were all up-regulated by increased AA levels. This result is in line with the foresaid elevated fatty acids biosynthetic gene expression, as elevated glycolysis can render more available substrates to support the enhanced fatty acid biosynthesis and increased NADPHdemanding. Given that glycolysis is known to be positively regulated by the transcription factors HIF- $1 \alpha$ and SREBP1c $[68,82]$, and both HIF- $1 \alpha$ and SREBP1c mRNA levels were inhibited by rapamycin in the current study, we thus suggest that high levels of AAs upregulated hepatic glycolysis through an mTORC1-dependent manner as well. This deduction is consistent with the observation of Lansard et al. [27], who observed that insulin combined with AAs activated TOR signaling pathway and up-regulated the expression of GK, 6PF1K and PK. As for GLUT2 gene expression, despite it was significantly decreased by insulin and up-regulated by rapamycin and elevated AAs, all the changes were quite minor, confirming that GLUT2, which has low affinity for glucose, is poorly regulated by metabolic factors [83]. 
AAs modulated AA catabolism and p38 MAPK phosphorylation

AAs are not only signaling molecules, but are also glucose and fatty acids precursors, which can supply carbon skeleton for hepatic gluconeogenesis and lipogenesis via AA catabolism [84]. As expected, increased AA levels markedly elevated the expression of genes related to AA catabolism (SD, ALAT2, ASAT2, BCKDE1 $\alpha$, BCKDE2 and BCKDK), indicating that elevated AA levels promoted hepatic fatty acid biosynthesis and glucose metabolism not only through modulating relevant signaling pathways, but also serving as gluconeogenic and lipogenic substrates by promoting AA catabolism. The present study also demonstrated that several AA catabolic genes were controlled by the mTOR pathway. Further studies are needed to explore the mechanisms linking these signaling pathways to AA catabolic gene expression.

p38 MAPK phosphorylation was not affected by insulin in hepatocytes, which is consistent with previous demonstrations showing that insulin-mediated p38 MAPK activation mainly occur in adipocytes and skeletal muscle [85]. p38 phosphorylation was insensitive to rapamycin, indicating that high levels of AAs decreased p38 phosphorylation through an mTORC1-independent manner. The AA-induced decrease of p38 phosphorylation was associated with the up-regulation of hepatic lipogenic, G6PDH and gluconeogenic gene expression. These results are compatible with previous reports indicating that $\mathrm{p} 38$ MAPK negatively regulates hepatic lipogentic and G6PDH mRNA levels [86, 87]. However, they contrast with the other studies reporting that p38 plays a stimulatory role in hepatic gluconeogenic gene expression [88, 89]. Nevertheless, we uncovered a new player involved in AA signaling, which confirmed previous deductions by Casas-Terradellas et al. [90] and may provide new insights into the understanding of nutrients-mediated intermediary metabolism.

\section{Conclusions and prospects}

Taken together, we demonstrated that, in primary trout hepatocytes, increased AA levels could (i) up-regulate fatty acid biosynthetic gene expression through an mTORC1dependent manner, (ii) attenuate insulin-mediated repression on hepatic gluconeogenesis through elevated IRS-1 phosphorylation on $\mathrm{Ser}^{302}$, which in turn impairs the activation of Akt pathway and weakens insulin action, (iii) elevate AA catabolic gene expression, and (iiii) partly suppress p38 MAPK phosphorylation. The results that, under excessive AAs conditions, insulin partially lost its ability to suppress gluconeogenesis but continued to promote fatty acid biosynthetic gene expression, resemble the pathological features observed in the insulin-resistant state $[91,92]$, which further highlights the potential of carnivorous fish to be used as a natural model for the study of common mammalian pathologies. Future studies are needed to determine which AA truly contributes to mTORC1 activation, and gene expression regulation, and how dietary AA profiles may influence these regulations.

\section{Acknowledgments}

W. Dai gratefully acknowledges the financial assistance provided by the China Scholarship Council (CSC, File No. 2011633111) for his doctoral fellowship.

We thank K. Dias, V. Véron, A. Herman and M. Cluzeaud for technical assistance in the laboratory. We also acknowledge the technical staff of the INRA experimental fish farm at Saint Pee sur Nivelle (P. Aguirre and Y. Mercier) for fish rearing.

\section{Disclosures Statement}

No conflicts of interest, financial or otherwise, are declared by the authors. 


\section{Cellular Physiology Cell Physiol Biochem 2015;36:1084-1100

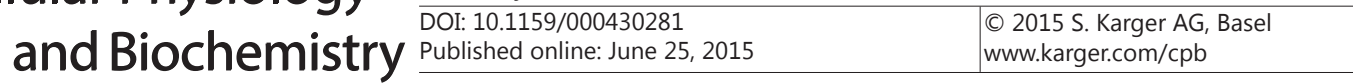

\section{References}

1 Yecies JL, Zhang HH, Menon S, Liu S, Yecies D, Lipovsky AI, Gorgun C, Kwiatkowski DJ, Hotamisligil GS, Lee CH, Manning BD: Akt stimulates hepatic srebp1c and lipogenesis through parallel mtorc1-dependent and independent pathways. Cell Metabol 2011;14:21-32.

2 Manning BD, Cantley LC: Akt/pkb signaling: Navigating downstream. Cell 2007;129:1261-1274.

3 Accili D, Arden KC: Foxos at the crossroads of cellular metabolism, differentiation, and transformation. Cell 2004;117:421-426.

4 Li X, Monks B, Ge Q, Birnbaum MJ: Akt/pkb regulates hepatic metabolism by directly inhibiting pgc-1alpha transcription coactivator. Nature 2007;447:1012-1016.

5 Horton JD, Goldstein JL, Brown MS: Srebps: Activators of the complete program of cholesterol and fatty acid synthesis in the liver. J Clin Invest 2002;109:1125-1131.

6 Shao W, Espenshade PJ: Expanding roles for srebp in metabolism. Cell metabolism 2012;16:414-419.

7 Baranowski M, Zabielski P, Blachnio-Zabielska AU, Harasim E, Chabowski A, Gorski J: Insulin-sensitizing effect of lxr agonist t0901317 in high-fat fed rats is associated with restored muscle glut4 expression and insulin-stimulated as160 phosphorylation. Cell Physiol Biochem 2014;33:1047-1057.

8 Newsholme P, Brennan L, Rubi B, Maechler P: New insights into amino acid metabolism, beta-cell function and diabetes. Clin Sci (Lond) 2005;108:185-194.

9 Cheng Z, Tseng Y, White MF: Insulin signaling meets mitochondria in metabolism. Trends Endocrinol Metab 2010;21:589-598.

10 Bar-Peled L, Sabatini DM: Regulation of mtorc1 by amino acids. Trends Cell Biol 2014;24:400-406.

11 Shimobayashi M, Hall MN: Making new contacts: The mtor network in metabolism and signalling crosstalk. Nat Rev Mol Cell Biol 2014;15:155-162.

12 Laplante M, Sabatini DM: Regulation of mtorc1 and its impact on gene expression at a glance. J Cell Sci 2013;126:1713-1719.

13 Tremblay F, Lavigne C, Jacques H, Marette A: Role of dietary proteins and amino acids in the pathogenesis of insulin resistance. Annu Rev Nutr 2007;27:293-310.

14 Boura-Halfon S, Zick Y: Phosphorylation of irs proteins, insulin action, and insulin resistance. Am J PhysiolEndoc M 2009;296:E581-E591.

15 Lynch CJ, Adams SH: Branched-chain amino acids in metabolic signalling and insulin resistance. Nature Rev Endocrinol 2014;10:723-736.

16 Um SH, D'Alessio D, Thomas G: Nutrient overload, insulin resistance, and ribosomal protein s6 kinase 1, s6k1. Cell Metabol 2006;3:393-402.

17 Feng YY, Xu XQ, Ji CB, Shi CM, Guo XR, Fu JF: Aberrant hepatic microrna expression in nonalcoholic fatty liver disease. Cell Physiol Biochem 2014;34:1983-1997.

18 Wagner EF, Nebreda AR: Signal integration by jnk and p38 mapk pathways in cancer development. Nat Rev Cancer 2009;9:537-549.

19 Ono K, Han J: The p38 signal transduction pathway: Activation and function. Cell Signal 2000;12:1-13.

20 Gehart H, Kumpf S, Ittner A, Ricci R: Mapk signalling in cellular metabolism: Stress or wellness? EMBO reports 2010;11:834-840.

21 Cao W, Collins QF, Becker TC, Robidoux J, Lupo EG Jr, Xiong Y, Daniel KW, Floering L, Collins S: P38 mitogenactivated protein kinase plays a stimulatory role in hepatic gluconeogenesis. J Biol Chem 2005;280:4273142737.

22 Xiong Y, Collins QF, An J, Lupo E, Jr., Liu HY, Liu D, Robidoux J, Liu Z, Cao W: P38 mitogen-activated protein kinase plays an inhibitory role in hepatic lipogenesis. J Biol Chem 2007;282:4975-4982.

23 Schermerhorn T: Normal glucose metabolism in carnivores overlaps with diabetes pathology in noncarnivores. Front Endocrinol (Lausanne) 2013;4:188.

24 Hemre GI, Mommsen TP, Krogdahl A: Carbohydrates in fish nutrition: Effects on growth, glucose metabolism and hepatic enzymes. Aquacult Nutr 2002;8:175-194.

25 Plagnes-Juan E, Lansard M, Seiliez I, Medale F, Corraze G, Kaushik S, Panserat S, Skiba-Cassy S: Insulin regulates the expression of several metabolism-related genes in the liver and primary hepatocytes of rainbow trout (oncorhynchus mykiss). J Exp Biol 2008;211:2510-2518.

26 Kirchner S, Kaushik S, Panserat S: Low protein intake is associated with reduced hepatic gluconeogenic enzyme expression in rainbow trout (oncorhynchus mykiss). J Nutr 2003;133:2561-2564. 


\section{Cellular Physiology Cell Physiol Biochem 2015;36:1084-1100 \begin{tabular}{l|l} 
DOI: 10.1159/000430281 & $\begin{array}{l}\text { O 2015 S. Karger AG, Basel } \\
\text { www.karger.com/cpb }\end{array}$ \\
\hline
\end{tabular}}

27 Lansard M, Panserat S, Plagnes-Juan E, Seiliez I, Skiba-Cassy S: Integration of insulin and amino acid signals that regulate hepatic metabolism-related gene expression in rainbow trout: Role of tor. Amino Acids 2010;39:801-810.

28 Seiliez I, Panserat S, Lansard M, Polakof S, Plagnes-Juan E, Surget A, Dias K, Larquier M, Kaushik S, Skiba-Cassy S: Dietary carbohydrate-to-protein ratio affects tor signaling and metabolism-related gene expression in the liver and muscle of rainbow trout after a single meal. Am J Physiol-Reg I 2011;300:R733-R743.

29 Dias J, Alvarez MJ, Diez A, Arzel J, Corraze G, Bautista JM, Kaushik SJ: Regulation of hepatic lipogenesis by dietary protein/energy in juvenile european seabass (dicentrarchus labrax). Aquaculture 1998;161:169186.

30 Figueiredo-Silva AC, Corraze G, Rema P, Sanchez-Gurmaches J, Gutierrez J, Valente LMP: Blackspot seabream (pagellus bogaraveo) lipogenic and glycolytic pathways appear to be more related to dietary protein level than dietary starch type. Aquaculture 2009;291:101-110.

31 Lansard M, Panserat S, Plagnes-Juan E, Dias K, Seiliez I, Skiba-Cassy S: L-leucine, l-methionine, and l-lysine are involved in the regulation of intermediary metabolism-related gene expression in rainbow trout hepatocytes. J Nutr 2011;141:75-80.

32 Dai W, Panserat S, Mennigen JA, Terrier F, Dias K, Seiliez I, Skiba-Cassy S: Post-prandial regulation of hepatic glucokinase and lipogenesis requires the activation of torc1 signalling in rainbow trout (oncorhynchus mykiss). J Exp Biol 2013;216:4483-4492.

33 Segner H: Isolation and primary culture of teleost hepatocytes. Comp Biochem Physiol A: Comp Physiol 1998;120:71-81.

34 Ferraris M, Radice S, Catalani P, Francolini M, Marabini L, Chiesara E: Early oxidative damage in primary cultured trout hepatocytes: A time course study. Aquatic Toxicology 2002;59:283-296.

35 del sol Novoa M, Capilla E, Rojas P, Baro J, Gutierrez J, Navarro I: Glucagon and insulin response to dietary carbohydrate in rainbow trout (oncorhynchus mykiss). Gen Comp Endocrinol 2004;139:48-54.

36 Dai WW, Panserat S, Terrier F, Seiliez I, Skiba-Cassy S: Acute rapamycin treatment improved glucose tolerance through inhibition of hepatic gluconeogenesis in rainbow trout (oncorhynchus mykiss). Am J Physiol-Reg I 2014;307:R1231-R1238.

37 SIGENAE: Information system of breeding animals' genome. Http://www.Sigenae. Org/.

38 Kamalam BS, Panserat S, Aguirre P, Geurden I, Fontagne-Dicharry S, Medale F: Selection for high muscle fat in rainbow trout induces potentially higher chylomicron synthesis and pufa biosynthesis in the intestine. Comp Biochem Physiol A Mol Integr Physiol 2013;164:417-427.

39 Skiba-Cassy S, Lansard M, Panserat S, Medale F: Rainbow trout genetically selected for greater muscle fat content display increased activation of liver tor signaling and lipogenic gene expression. Am J Physiol-Reg I 2009;297:R1421-R1429.

40 Polakof S, Skiba-Cassy S, Panserat S: Glucose homeostasis is impaired by a paradoxical interaction between metformin and insulin in carnivorous rainbow trout. Am J Physiol Regul Integr Comp Physiol 2009;297:R1769-1776.

41 Cruz-Garcia L, Minghetti M, Navarro I, Tocher DR: Molecular cloning, tissue expression and regulation of liver $\mathrm{x}$ receptor (lxr) transcription factors of atlantic salmon (salmo salar) and rainbow trout (oncorhynchus mykiss). Comp Biochem Physiol B Biochem Mol Biol 2009;153:81-88.

42 Seiliez I, Panserat S, Lansard M, Polakof S, Plagnes-Juan E, Surget A, Dias K, Larquier M, Kaushik S, Skiba-Cassy S: Dietary carbohydrate-to-protein ratio affects tor signaling and metabolism-related gene expression in the liver and muscle of rainbow trout after a single meal. Am J Physiol Regul Integr Comp Physiol 2011;300:R733-743.

43 Cowley DJ, Sheridan MA: Insulin stimulates hepatic lipogenesis in rainbow-trout, oncorhynchus-mykiss. Fish Physiol Biochem 1993;11:421-428.

44 Saltiel AR, Kahn CR: Insulin signalling and the regulation of glucose and lipid metabolism. Nature 2001;414:799-806.

45 Casas-Terradellas E, Tato I, Bartrons R, Ventura F, Rosa JL: Erk and p38 pathways regulate amino acid signalling. Biochim Biophys Acta 2008;1783:2241-2254.

46 Walton MJ, Cowey CB: Aspects of intermediary metabolism in salmonid fish. Comp Biochem Phys B 1982;73:59-79. 


\section{Cellular Physiology Cell Physiol Biochem 2015;36:1084-1100 \begin{tabular}{l|l} 
DOI: 10.1159/000430281 & $\begin{array}{l}\text { O 2015 S. Karger AG, Basel } \\
\text { www.karger.com/cpb }\end{array}$ \\
\hline
\end{tabular}}

47 Dann SG, Selvaraj A, Thomas G: Mtor complex1-s6k1 signaling: At the crossroads of obesity, diabetes and cancer. Trends Mol Med 2007;13:252-259.

48 Harrington LS, Findlay GM, Gray A, Tolkacheva T, Wigfield S, Rebholz H, Barnett J, Leslie NR, Cheng S, Shepherd PR, Gout I, Downes CP, Lamb RE: The tsc1-2 tumor suppressor controls insulin-pi3k signaling via regulation of irs proteins. J Cell Biol 2004;166:213-223.

49 Tremblay F, Marette A: Amino acid and insulin signaling via the mtor/p70 s6 kinase pathway - a negative feedback mechanism leading to insulin resistance in skeletal muscle cells. J Biol Chem 2001;276:3805238060.

50 Patti ME, Brambilla E, Luzi L, Landaker EJ, Kahn CR: Bidirectional modulation of insulin action by amino acids. J Clin Invest 1998;101:1519-1529.

51 Takano T, Usui I, Haruta T, Kawahara J, Uno T, Iwata M, Kobayashi M: Mammalian target of rapamycin pathway regulates insulin signaling via subcellular redistribution of insulin receptor substrate 1 and integrates nutritional signals and metabolic signals of insulin. Mol Cell Biol 2001;21:5050-5062.

52 Layman DK, Shiue H, Sather C, Erickson DJ, Baum J: Increased dietary protein modifies glucose and insulin homeostasis in adult women during weight loss. J Nutr 2003;133:405-410.

53 Tremblay F, Krebs M, Dombrowski L, Brehm A, Bernroider E, Roth E, Nowotny P, Waldhausl W, Marette A, Roden M: Overactivation of s6 kinase 1 as a cause of human insulin resistance during increased amino acid availability. Diabetes 2005;54:2674-2684.

54 Cowey CB, Knox D, Walton MJ, Adron JW: Regulation of gluconeogenesis by diet and insulin in rainbowtrout (salmo-gairdneri). Br J Nutr 1977;38:463-470.

55 Hilton JW, Atkinson JL: Response of rainbow-trout (salmo-gairdneri) to increased levels of available carbohydrate in practical trout diets. Br J Nutr 1982;47:597-607.

56 Walton MJ: Metabolic effects of feeding a high protein-low carbohydrate-diet as compared to a low proteinhigh carbohydrate-diet to rainbow-trout salmo-gairdneri. Fish Physiol Biochem 1986;1:7-15.

57 Enes P, Panserat S, Kaushik S, Oliva-Teles A: Effect of normal and waxy maize starch on growth, food utilization and hepatic glucose metabolism in european sea bass (dicentrarchus labrax) juveniles. Comp Biochem Phys A 2006;143:89-96.

58 Kamalam BS, Medale F, Kaushik S, Polakof S, Skiba-Cassy S, Panserat S: Regulation of metabolism by dietary carbohydrates in two lines of rainbow trout divergently selected for muscle fat content. J Exp Biol 2012;215:2567-2578.

59 Cheng ZY, White MF: The aktion in non-canonical insulin signaling. Nat Med 2012;18:351-353.

60 Khamzina L, Veilleux A, Bergeron S, Marette A: Increased activation of the mammalian target of rapamycin pathway in liver and skeletal muscle of obese rats: Possible involvement in obesity-linked insulin resistance. Endocrinology 2005;146:1473-1481.

61 Haruta T, Uno T, Kawahara J, Takano A, Egawa K, Sharma PM, Olefsky JM, Kobayashi M: A rapamycinsensitive pathway down-regulates insulin signaling via phosphorylation and proteasomal degradation of insulin receptor substrate-1. Mol Endocrinol 2000;14:783-794.

62 Tremblay F, Gagnon A, Veilleux A, Sorisky A, Marette A: Activation of the mammalian target of rapamycin pathway acutely inhibits insulin signaling to akt and glucose transport in 3t3-l1 and human adipocytes. Endocrinology 2005;146:1328-1337.

63 Linn T, Santosa B, Gronemeyer D, Aygen S, Scholz N, Busch M, Bretzel RG: Effect of long-term dietary protein intake on glucose metabolism in humans. Diabetologia 2000;43:1257-1265.

64 Rossetti L, Rothman DL, DeFronzo RA, Shulman GI: Effect of dietary protein on in vivo insulin action and liver glycogen repletion. Am J Physiol 1989;257:E212-219.

65 Slawson C, Copeland RJ, Hart GW: O-gicnac signaling: A metabolic link between diabetes and cancer? Trends Biochem Sci 2010;35:547-555.

66 Mommsen TP, Plisetskaya EM: Insulin in fishes and agnathans - history, structure, and metabolicregulation. Rev Aquat Sci 1991;4:225-259.

67 Floyd JC, Jr., Fajans SS, Conn JW, Knopf RF, Rull J: Stimulation of insulin secretion by amino acids. J Clin Invest 1966;45:1487-1502.

68 Duvel K, Yecies JL, Menon S, Raman P, Lipovsky AI, Souza AL, Triantafellow E, Ma QC, Gorski R, Cleaver S, Heiden MGV, MacKeigan JP, Finan PM, Clish CB, Murphy LO, Manning BD: Activation of a metabolic gene regulatory network downstream of mtor complex 1. Mol Cell 2010;39:171-183. 


\section{Cellular Physiology Cell Physiol Biochem 2015;36:1084-1100 \begin{tabular}{l|l} 
DOI: 10.1159/000430281 & $\begin{array}{l}\text { O 2015 S. Karger AG, Basel } \\
\text { www.karger.com/cpb }\end{array}$ \\
\hline
\end{tabular}}

69 Herzberg GR, Rogerson M: The role of dietary-protein in hepatic lipogenesis in the young-rat. Br J Nutr 1981;45:529-538.

70 Iritani N, Fukuda H, Tada K: Nutritional regulation of lipogenic enzyme gene expression in rat epididymal adipose tissue. J Biochem 1996;120:242-248.

71 Allee GL, O'Hea EK, Leveille GA, Baker DH: Influenza of dietary protein and fat on lipogenesis and enzymatic activity in pig adipose tissue. J Nutr 1971;101:869-878.

72 Rosebrough RW, Poch SM, Russell BA, Richards MP: Dietary protein regulates in vitro lipogenesis and lipogenic gene expression in broilers. Comp Biochem Physiol-Mol Int Physiol 2002;132:423-431.

73 Laurencikiene J, Ryden M: Liver x receptors and fat cell metabolism. Int J Obes (Lond) 2012;36:1494-1502.

74 Jeon TI, Osborne TF: Srebps: Metabolic integrators in physiology and metabolism. Trends Endocrinol Metab 2012;23:65-72.

75 Zhang W, Patil S, Chauhan B, Guo S, Powell DR, Le J, Klotsas A, Matika R, Xiao X, Franks R, Heidenreich KA, Sajan MP, Farese RV, Stolz DB, Tso P, Koo SH, Montminy M, Unterman TG: Foxo1 regulates multiple metabolic pathways in the liver: Effects on gluconeogenic, glycolytic, and lipogenic gene expression. J Biol Chem 2006;281:10105-10117.

76 Egea M, Meton I, Baanante IV: Sp1 and sp3 regulate glucokinase gene transcription in the liver of gilthead sea bream (sparus aurata). J Mol Endocrinol 2007;38:481-492.

77 Iynedjian PB: Molecular physiology of mammalian glucokinase. Cell Mol Life Sci 2009;66:27-42.

78 Matschinsky FM: Assessing the potential of glucokinase activators in diabetes therapy. Nat Rev Drug Discov 2009;8:399-416.

79 Postic C, Shiota M, Niswender KD, Jetton TL, Chen Y, Moates JM, Shelton KD, Lindner J, Cherrington AD, Magnuson MA: Dual roles for glucokinase in glucose homeostasis as determined by liver and pancreatic beta cell-specific gene knock-outs using cre recombinase. J Biol Chem 1999;274:305-315.

80 Jin JY, Panserat S, Kamalam BS, Aguirre P, Veron V, Medale F: Insulin regulates lipid and glucose metabolism similarly in two lines of rainbow trout divergently selected for muscle fat content. Gen Comp Endocrinol 2014;204:49-59.

81 Polakof S, Skiba-Cassy S, Choubert G, Panserat S: Insulin-induced hypoglycaemia is co-ordinately regulated by liver and muscle during acute and chronic insulin stimulation in rainbow trout (oncorhynchus mykiss). J Exp Biol 2010;213:1443-1452.

82 Massa ML, Gagliardino JJ, Francini F: Liver glucokinase: An overview on the regulatory mechanisms of its activity. Iubmb Life 2011;63:1-6.

83 Mueckler M, Thorens B: The slc2 (glut) family of membrane transporters. Mol Aspects Med 2013;34:121138.

84 Berg JM, Tymoczko JL, Stryer L: Biochemistry, ed 7th edition. New York, W H Freeman, 2010.

85 Antonescu CN, Huang C, Niu W, Liu Z, Eyers PA, Heidenreich KA, Bilan PJ, Klip A: Reduction of insulinstimulated glucose uptake in 16 myotubes by the protein kinase inhibitor sb203580 is independent of p38mapk activity. Endocrinology 2005;146:3773-3781.

86 Xiong Y, Collins QF, An J, Lupo E, Liu HY, Liu DL, Robidoux J, Liu ZQ Cao WH: P38 mitogen-activated protein kinase plays an inhibitory role in hepatic lipogenesis. J Biol Chem 2007;282:4975-4982.

87 Talukdar I, Szeszel-Fedorowicz W, Salati LM: Arachidonic acid inhibits the insulin induction of glucose-6phosphate dehydrogenase via p38 map kinase. J Biol Chem 2005;280:40660-40667.

88 Cao WH, Collins QF, Becker TC, Robidoux J, Lupo EG, Xiong Y, Daniel KW, Floering L, Collins S: P38 mitogenactivated protein kinase plays a stimulatory role in hepatic gluconeogenesis. J Biol Chem 2005;280:4273142737.

89 Qiao LP, MacDougald OA, Shao JH: Ccaat/enhancer-binding protein alpha mediates induction of hepatic phosphoenolpyruvate carboxykinase by p38 mitogen-activated protein kinase. J Biol Chem 2006;281:24390-24397.

90 Casas-Terradellas E, Tato I, Bartrons R, Ventura F, Rosa JL: Erk and p38 pathways regulate amino acid signalling. Bba-Mol Cell Res 2008;1783:2241-2254.

91 Samuel VT, Shulman GI: Mechanisms for insulin resistance: Common threads and missing links. Cell 2012;148:852-871.

92 Kahn SE, Hull RL, Utzschneider KM: Mechanisms linking obesity to insulin resistance and type 2 diabetes. Nature 2006;444:840-846. 